\title{
HABITABILIDAD BÁSICA EN LA ENSEÑANZA
}

\author{
Belén Gesto (Arquitecta - Profesora asociada del DUyOT)
}

Tomé la decisión de estudiar arquitectura hace ya veinte años después de leer La ciudad de la Alegría, de Dominique Lapierre, y descubrir lo que podía ser la vida en un slum (tugurio) -que hasta entonces desconocía-. Y me aventuré en la carrera dispuesta a aprender a "hacer casas buenas, bonitas y baratas" -como me decía con palabras ingenuas y juveniles-, que fuesen capaces de dar dignidad a aquellos que poco tenían, que vivían en la miseria, hacinados en pequeños cuartos, en condiciones insalubres, compartiendo letrinas cada mañana y un sólo grifo de agua y que, conscientes de que por todo ello su esperanza de vida era menor, luchaban por lograr unas condiciones mínimas de habitabilidad.

En los seis años de carrera no encontré el espacio académico en la ETSAM que respondiese a las inquietudes con las que había comenzado y que me ayudase a formarme para ser capaz de dar respuesta, como arquitecta , a aquello a lo que me sentía llamada. Fue en sexto curso cuando por primera vez un profesor, Luis Felipe Teixidor, puso en clase una imagen de un tugurio, con la que se nos mostraba esa otra realidad -precaria- que se podía encontrar en algunas ciudades del planeta. Y fue gracias a él que supe de la existencia de un Curso de Posgrado ${ }^{17}$ y conocí a los dos profesores a los que a día de hoy, más de mil alumnos les debemos nuestros conocimientos en lo que ellos denominaban Habitabilidad Básica (HaB, en adelante). Esos profesores, a los que personalmente debo parte de lo que hoy soy, son Felipe Colavidas y Julián Salas, profesores del DUyOT ${ }^{18}$. Era el año 2000.

Hacía cuatro años -después de Hábitat $\mathrm{II}^{19}{ }_{-}$, habían iniciado una trayectoria académica juntos con la que cubrir un vacío en la enseñanza universitaria, en el campo de la Cooperación al Desarrollo y de los Asentamientos Humanos en países en desarrollo -en aquel momento denominados 'Tercer Mundo'-. Y durante casi veinte años -primero juntos, y luego por separado-, se han esforzado por intentar aportar instrumentos de ordenación territorial, planeamiento, urbanización y alojamiento a profesionales que deseaban trabajar para dar respuesta al hambre de vivienda20. Fundaron el ICHaB (Instituto de Cooperación en Habitabilidad Básica, uno de los primeros Grupos de Cooperación creados en la UPM) y en 2007 lograron el reconocimiento de Cátedra UNESCO de Habitabilidad Básica.

Incorporaron así la $\mathrm{HaB}$ en el ámbito académico, en la enseñanza universitaria. Primero, con la formación en posgrado que comenzaron con una asignatura de doctorado y el Curso de Especialización. Para luego, con el apoyo del DUyOT, ofertar

17 Curso de "Cooperación para el Desarrollo de Asentamientos Humanos en el Tercer Mundo" que, en 2016 iniciará su XIX edición. Comenzó siendo Curso de Especialización. En la actualidad es un Título de Experto.

18 Felipe Colavidas Espinosa, Dr. Arquitecto, profesor titular del DUyOT y Julián Salas Serrano, Dr. Ingeniero Industrial, investigador del CSIC y profesor ad honorem del DUyOT.

19 La Segunda Conferencia Mundial sobre Asentamientos Humanos que había tenido lugar en Estambul en 1996.

20 El libro de Julián Salas, Contra el hambre de vivienda, publicado en 1998 (editorial Escala, Colombia), se convirtió en referente dentro y fuera de España, especialmente en América Latina. 
en los estudios de Arquitectura del Plan 96 de la ETSAM, la asignatura optativa 715 Habitabilidad Básica que ha dado la oportunidad, a aquellos que tenían la inquietud, de poder formarse en ello durante sus estudios de grado ${ }^{21}$. Oportunidad que, hace veinte años, no tuve, y que sinceramente considero un gran aporte -aunque sea modesto- en y de nuestra Universidad.

HaB es, en palabras del profesor Colavidas, "la que colma las necesidades esenciales de cobijo que tenemos todas las personas. Su satisfacción supone que se cubran las urgencias residenciales del vivir, pero no sólo las que se refieren al mero cobijo, sino también a los espacios públicos, infraestructuras y servicios elementales que constituyen, en conjunto, un asentamiento propicio para la reproducción vital. Una $\mathrm{HaB}$ que atiende además de las necesidades de alojamiento y residencia -del estar-, las de producción -del ser material activo-". La HaB comprende, por tanto, abastecimiento de agua potable, saneamiento, eliminación de desechos, asistencia social básica, servicios de transporte y comunicaciones, caminos de bajo coste, suministro de energía, servicios de salud, escuelas, seguridad ciudadana, espacios para el ocio, viviendas semilla,... mediante construcciones e infraestructuras de bajo coste que deben ser capaces de mejorar paulatinamente.

En el ámbito internacional, las reflexiones que tuvieron lugar en la Conferencia sobre Asentamientos Humanos en 1976 (Hábitat I), supusieron una enorme sorpresa para muchos gobiernos -en particular, de América Latina-. Esta conferencia significó una apertura de miras ante una realidad que no se quería atender y el primer paso a la incorporación de nuevas estrategias y nuevas concepciones de la problemática de la habitabilidad precaria, así como de las posibles soluciones. Prueba de la nueva conciencia mundial fue la creación en 1978 del primer Centro de las Naciones Unidas para los Asentamientos Humanos (UNCHS). Este centro en 2001, tras la cumbre de los Objetivos de Desarrollo del Milenio, (ODM), se transformó en el Programa de las Naciones Unidas para los Asentamientos Humanos ONU-Habitat (UN-Habitat).

Fue precisamente a raíz de los ODM, en concreto de su meta 11 (conocida como "Cities without slums") dentro del objetivo 7 de "Garantizar la sostenibilidad del medio ambiente", cuando se hizo preciso definir tugurio y establecer los parámetros que permitiesen medir el cumplimiento de la meta que se había fijado "Haber mejorado considerablemente, para el año 2020, la vida de por lo menos 100 millones de habitantes de tugurios".

El informe de UN-HABITAT "Slums of the world: The face of urban poverty in the new millennium?", de 2003, recoge esos indicadores y determina que el grado de precariedad de un asentamiento urbano puede medirse en función del acceso de los hogares a cinco parámetros: acceso a agua potable, acceso a saneamiento básico, área suficiente para vivir, durabilidad de la vivienda y tenencia segura ${ }^{22}$. Se considera

${ }^{21}$ En el nuevo Plan 2010, se imparte el Taller Experimental Habitabilidad Básica

22 Acceso al agua potable: Se considera que un hogar tiene acceso al suministro de agua potable si dispone de al menos 20 litros de agua por persona y día, a un precio inferior del $10 \%$ del total de los ingresos del hogar, sin que los miembros del hogar deban someterse a un esfuerzo extremo, especialmente las mujeres y los niños (menos de 1 hora al día). Acceso a saneamiento básico: Se considera que un hogar tiene acceso adecuado al saneamiento básico si sus miembros disponen de un sistema de eliminación de los excrementos, ya sea en forma de letrina privada o pública compartida por un número razonable de personas. Área suficiente para vivir, sin hacinamiento: Se considera que una vivienda proporciona un área suficiente para que sus miembros vivan si hay menos de tres personas por 
tugurio ('slum') un área de una ciudad en la que la mitad o más de su población carece de alguno de esos cinco parámetros (UN-HABITAT, 2003).

La cifra de personas viviendo en tugurios en las regiones en desarrollo en el 2012 era de 862,5 millones. Si bien se ha alcanzado la meta del Objetivo referida a la población de los tugurios, la cantidad de habitantes de estos barrios sigue aumentando en términos absolutos, debido en parte al ritmo vertiginoso del proceso de urbanización. Este proceso sigue siendo más rápido que las mejoras en los tugurios (UN-HABITAT, 2013). En 2012, los 862,5 millones de habitantes urbanos de las regiones en desarrollo que vivían en tugurios suponían un $33 \%$ de su población total urbana. En África subsahariana ese porcentaje era el más alto del planeta, del 62\%, siendo la región que además, según las estimaciones de Naciones Unidas, tendrá los mayores crecimientos demográficos y de tasas de urbanización de los próximos treinta años (UN, 2013).

En lo que al acceso a infraestructuras y servicios se refiere, cabría añadir dos datos relevantes: en 2012 había 748 millones de personas que seguían utilizando agua de fuentes no mejoradas y más de 2.500 millones no tenían acceso a saneamiento mejorado, un $10 \%$ y un $35 \%$ del total de población mundial respectivamente (UN, 2014). Es más, sigue inquietando aún la calidad y la seguridad de muchas de las fuentes de agua potable consideradas mejoradas, lo que hace pensar que la cantidad de personas sin acceso al agua potable segura podría ser incluso dos o tres veces superior a las estimaciones oficiales. De forma general, es preciso -y positivo- señalar que los valores porcentuales de precariedad se están reduciendo, aunque en valores absolutos, debido al crecimiento demográfico, las cifras sigan creciendo. Se puede por tanto afirmar -considerando sólo el último parámetro relativo a la falta de saneamiento mejorado en el mundo- que más del $35 \%$, una de cada tres personas en el mundo, vive en condiciones de habitabilidad precaria.

Y no se trata sólo de un problema urbano, la habitabilidad precaria rural es más numerosa -y severa- que la urbana. Ocho de cada diez personas sin acceso a fuente mejorada de agua vive en el ámbito rural, así como siete de cada diez que carece de saneamiento mejorado (UN, 2014). Sin olvidar la cifra récord alcanzada al final de 2013 de 51,2 millones de personas en todo el mundo desplazadas forzosamente como consecuencia de la persecución, de los conflictos, por la violencia generalizada y a causa de las violaciones de los derechos humanos que, en gran parte, se encuentran en campamentos "provisionales", fundamentalmente asistidos por ACNUR.

Afortunadamente, puedo decir que la Habitabilidad Básica se ha asentado en la ETSAM. Su incorporación a nuestra enseñanza universitaria ha brindado la oportunidad a los estudiantes de poder elegir una formación que, durante años, y pese a las necesidades que en el escenario internacional se hacían patentes, no se

habitación, con un mínimo de $4 \mathrm{~m}^{2}$ por habitación. Durabilidad de la vivienda, calidad estructural: Una vivienda se considera duradera si está construida en un emplazamiento no peligroso y tiene una estructura permanente y adecuada para proteger a sus habitantes de las inclemencias del tiempo tales como la lluvia, el calor, el frío y la humedad. Tenencia segura: Se considera que todos los individuos y grupos tienen derecho a contar con una protección eficaz del Estado contra los desalojos injustos forzados, considerándose que se cuenta con tenencia segura cuando existen pruebas documentales que se puedan utilizar para comprobar el derecho a la tenencia y cuando existe una protección de hecho o de derecho contra los desalojos forzados (UN-HABITAT, 2003). 
ofertaba. Nuestra formación universitaria sólo se preocupaba de preparar profesionales que atendiesen las demandas de poco más de un $20 \%$ de la población mundial -formación que, sin lugar a dudas, es necesaria-, pero que no aportaba las herramientas necesarias para trabajar en procesos que poco tienen que ver con los que nos enseñaban en las aulas. Debemos saber que en materia de vivienda, se estima que 7 de cada 10 viviendas que se hacen en el mundo son auto-construidas al margen del sector formal mercantil, porque el mercado formal no tiene capacidad de respuesta ante el crecimiento urbano en los países en vías de desarrollo, por lo que la gente -sin capacidad solvente- se construye sus viviendas o busca sus propias soluciones (DAVIS, 2007).

Este año se cumple la fecha meta de los ODM -que no procede analizar aquí-, dejando de manifiesto que aún hay trabajo por hacer y por ello, desde hace tres años se está preparando la Agenda de Desarrollo Post 2015 con un nuevo conjunto de objetivos -un total de 17-, esta vez denominados Objetivos de Desarrollo Sostenible (ODS). Sigue siendo necesaria, pues, la formación de profesionales de todas las disciplinas dispuestos a trabajar por intentar alcanzar estos nuevos Objetivos y luchar por hacer universal el acceso a la Habitabilidad Básica.

\section{REFERENCIAS BIBLIOGRÁFICAS:}

DAVIS, Ian (2007) Planeta de Ciudades Miseria. Madrid: Editorial FOCA

UN-United Nations (2014) Objetivos de Desarrollo del Milenio. Informe de 2014. Nueva York: Naciones Unidas

UN-HABITAT (2003) Slums of the World: The face of urban poverty in the new millenium?. Nairobi (Kenia): United Nations Human Settlements Programme

UN-HABITAT (2013) Planning and Design for Sustainable Urban Mobility: Global Report on Human Settlements 2013. Oxon (Reino Unido): Earthscan, Routledge 